\title{
MEMÓRIA, ESQUECIMENTO E ATUALIDADE: UMA ABORDAGEM DISCURSIVA
}

\author{
Thaís Aparecida Zorzela (PPGEL-UEL) \\ tzorzelaa@gmail.com \\ Orientadora: Prof. ${ }^{\text {a }}$ Dr. ${ }^{\text {a }}$ Mariângela Peccioli Galli Joanilho
}

Pautando-nos em uma perspectiva materialista do discurso, pretendemos, neste trabalho, descrever como os conceitos de memória e esquecimento são abordados pela da Análise de Discurso de orientação francesa. Enquanto teoria que visa à compreensão dos efeitos de sentidos dos enunciados, os princípios fundados por Michel Pêcheux concebem a linguagem de maneira integrativa, ou seja, a partir de seu entorno sócio-histórico. Nesse sentido, sob um olhar discursivo, efetivaremos possíveis leituras sobre o processo de (res)significação de imagens recortadas de diferentes contextos: a Ditadura Militar, período de repressão e censura que, no Brasil, perdurou de 1964 a 1985 e a Batalha do Centro Cívico de 29 de abril de 2015, dia em que o atual governador do estado, Beto Richa, deu ordens para que a polícia agisse violentamente contra servidores públicos em suas manifestações. Buscaremos, assim, compreender as condições de produção dos dizeres e como os conceitos abordados contribuem com o movimento dos sentidos, afetados pela história.

Palavras-chave: Análise de Discurso; Memória; Esquecimento.

\section{INTRODUÇÃO}

Em perspectivas ligadas ao discurso são concebidas as relações entre homem e realidade social. A partir dos estudos no projeto de pesquisa "Produção de sentidos e significação na história: memória e discurso nas ciências da linguagem", coordenado pela Profa. Dra. Mariângela Peccioli Galli Joanilho (LET/PPGEL-CLCH), da Universidade Estadual de Londrina, propusemo-nos realizar reflexões acerca dos processos e alterações históricas que atravessam os efeitos de sentido de enunciados, permitindo que eles signifiquem na história.

Para trabalhar com essas questões, descreveremos como os conceitos de memória e esquecimento, atrelados à discursividade, operam o processo de constituição dos sentidos em duas situações que envolvem política e repressão: a Ditadura Militar, que, prometendo uma alternativa ao populismo brasileiro, governou o país por mais de duas décadas por meio de atos institucionais. Em meio ao ufanismo dos governantes, que agiam violentamente contra grupos que contestavam o modelo, a população sofria com torturas, e a censura agia sobre a música, os meios de comunicação e artes em geral; e a Batalha do Centro Cívico de 29 de abril de 2015, que foi desencadeada pelos projetos enviados à Alep - Assembleia Legislativa - pelo governo do Paraná em fevereiro de 2015. Com o objetivo de resolver problemas administrativos, a proposta do governador Beto Richa contava com alguns projetos de medidas a serem votados. Dessa forma, dentre várias mudanças, alterações no fundo previdenciário dos servidores públicos do Paraná causaram a mobilização de servidores estaduais, alunos e outros grupos, resultando em greve. 


\section{SEMINÁRIO DE PESQUISA EM CIÊNCIAS HUMANAS - SEPECH \\ Humanidades, Estado e desafios didático-científicos \\ Londrina, 27 a 29 de julho de 2016}

Em 29 de abril, dia da votação do projeto enviado, conhecido como "pacotaço", houve, frente às manifestações, uma atitude tirânica comandada pelogoverno no Centro Cívico de Curitiba. Enquanto o projeto de lei era votado, a polícia militar recebeu ordens de avançar frente aos manifestantes, e centenas de servidores foram hostilizados e atingidos por balas de borracha, bombas e gás lacrimogêneo.

Diante do quadro citado e dos impactos que os acontecimentos (ainda) deixam na sociedade, buscaremos, para efetivar nosso estudos, respaldo em uma teoria materialista do discurso que visa aos efeitos de sentido produzidos pelos enunciados.

\section{PROCEDIMENTOS DA ANÁliSE DE DISCURSO: BREVE APRESENTAÇÃO}

Firmada enquanto disciplina na década de 1960, a Análise de Discurso de orientação francesa, ao unir bases da Linguística ao marxismo e à noção do inconsciente lacaniano, considera, em seus procedimentos analíticos, os efeitos de sentidos produzidos, ou seja, ao relacionar linguagem e exterioridade, a significação não pode ser tratada como única. Nesse sentido, a $\mathrm{AD}$ visa às determinações históricas das condições de produção dos enunciados proferidos, considerando a tríade fundamental de conceitos: discurso, sujeito e ideologia.

Interessam, para o analista, os posicionamentos discursivos assumidos por indivíduos os quais, clivados ideologicamente, são determinados por uma formação discursiva, que decide a constituição daquilo que pode ou não ser dito, assumem a posição sujeito. Nosso objetivo, nessa concepção de análise, é descrever por que um discurso é proferido da maneira que é e não de outra.

A noção de ideologia, para Marx, diz respeito ao conjunto de ideias que a classe dominante, a fim de dominar a classe dominada, utiliza, mascarando a realidade. A partir dessa ideia, a $\mathrm{AD}$, ao pensar em constituições, trabalha com uma

\footnotetext{
região de articulação da Linguística com a teoria histórica dos processos ideológicos e científicos, que, por sua vez, é parte da ciência das formações sociais: o sistema da língua é, de fato, o mesmo para o materialista e para o idealista, para o revolucionário e para o reacionário, para aquele que dispõe de um conhecimento dado e para aquele que não dispõe desse conhecimento. Entretanto, não se pode concluir, a partir disso, que esses diversos personagens tenham o mesmo discurso: a língua se apresenta, assim, como a base comum de processos discursivos diferenciados, que estão compreendidos nela na medida em que, como mostramos mais acima, os processos ideológicos simulam os processos científicos. (PÊCHEUX, 2014: 81)
}

Na teoria cujo objeto pauta-se no encontro da língua com a historicidade, nenhum discurso é novo, e o sujeito não é dono do seu dizer. Há sempre a manifestação de um já-dito, que relaciona os enunciados a uma memória, a uma historicidade e a uma ideologia. Eis a noção de interdiscurso, que diz respeito às formulações já realizadas e determinam outros possíveis dizeres. A memória, que ocorre no espaço interdiscursivo, torna possível a constituição dos discursos de sujeitos em determinado momento sóciohistórico na medida em que 


\section{SEMINÁRIO DE PESQUISA EM CIÊNCIAS HUMANAS - SEPECH \\ Humanidades, Estado e desafios didático-científicos \\ Londrina, 27 a 29 de julho de 2016}

Sustenta o dizer em uma estratificação de formulações já feitas mas esquecidas e que vão construindo uma história de sentidos. É sobre essa memória, de que não temos controle, que nossos sentidos se constroem, dando-nos a impressão de sabermos do que estamos falando. (ORLANDI, 2015: 52)

De acordo com Orlandi (2015: 31) "todo dizer, na realidade, se encontra na confluência de dois eixos: o da memória (constituição) e o da atualidade (formulação). E é desse jogo que tiram seus sentidos." Ao afetar a memória, o esquecimento, subdividido em duas categorias inerentes ao discurso por Pêcheux (2014), é, para a AD, estruturante, pois constitui a subjetividade e o processo de sentidos. $\mathrm{O}$ esquecimento de número 2, que é da ordem da enunciação, indica o equívoco do discurso, ou seja, que o dizer poderia ser outro. Essa significação se dá a partir de escolhas discursivas. Já o número 1 , de ordem ideológica, se dá pelo inconsciente e traz a ilusão de que somos donos daquilo que dizemos, que o discurso é novo. Dessa forma,

os sujeitos "esquecem" que já foi dito - e este não é um esquecimento voluntário - para, ao se identificarem com o que dizem, se constituírem em sujeitos. É assim que suas palavras adquirem sentido, é assim que eles se significam retomando palavras já existentes como se elas originassem neles e é assim que sentidos e sujeitos estão sempre em movimento, significando sempre de muitas e variadas maneiras. Sempre as mesmas mas, ao mesmo tempo, sempre outras. (ORLANDI, 2015, p. 34)

Analisaremos, a seguir, como esses conceitos estão inscritos no material recortado para análise.

\section{EFEITOS DE SENTIDO NA MATERIALIDADE IMAGÉTICA}

A fim de direcionar o olhar para os conceitos apresentados acima, fizemos um recorte de quatro imagens para a leitura. A primeira e a terceira estão inseridas no contexto da Ditadura Militar. A segunda e quarta, na Batalha do Centro Cívico.

Segundo Orlandi (2015: 50-51)

A condição da linguagem é a incompletude. Nem sujeitos nem sentidos estão completos, já feitos, constituídos definitivamente. Constituem-se e funcionam sob o modo de entremeio, da relação, da falta, do movimento. (...) Ao dizer, o sujeito significa em condições determinadas, impelido, de um lado, pela língua, e, de outro, pelo mundo, pela sua experiência, por fatos que reclamam sentidos, e também por sua memória discursiva, por um saber/poder/dever/dizer, em que os fatos fazem sentido por se inscreverem em formações discursivas que representam no discurso as injunções ideológicas.

Em nossas análises, não partiremos dos aspectos formais presentes nos textos visuais, pois esse trabalho cabe às teorias imanentes, ligadas ao texto. Tomaremos as imagens enquanto discursos. Olharemos, assim, para a exterioridade que as atravessam, 


\section{SEMINÁRIO DE PESQUISA EM CIÊNCIAS HUMANAS - SEPECH \\ Humanidades, Estado e desafios didático-científicos \\ Londrina, 27 a 29 de julho de 2016}

pois o que interessa, nessa produção, é como os sentidos são recuperados pela memória discursiva.

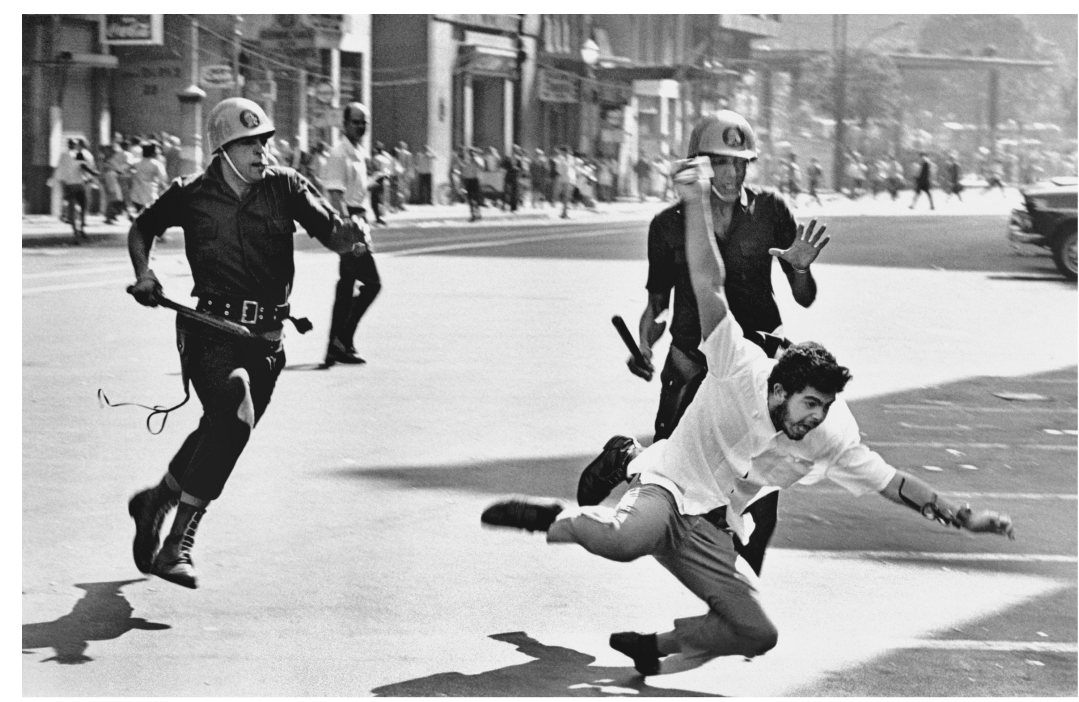

\section{Imagem 1}

Fonte: http://pensata.ig.com.br/index.php/tag/ditadura-militar/

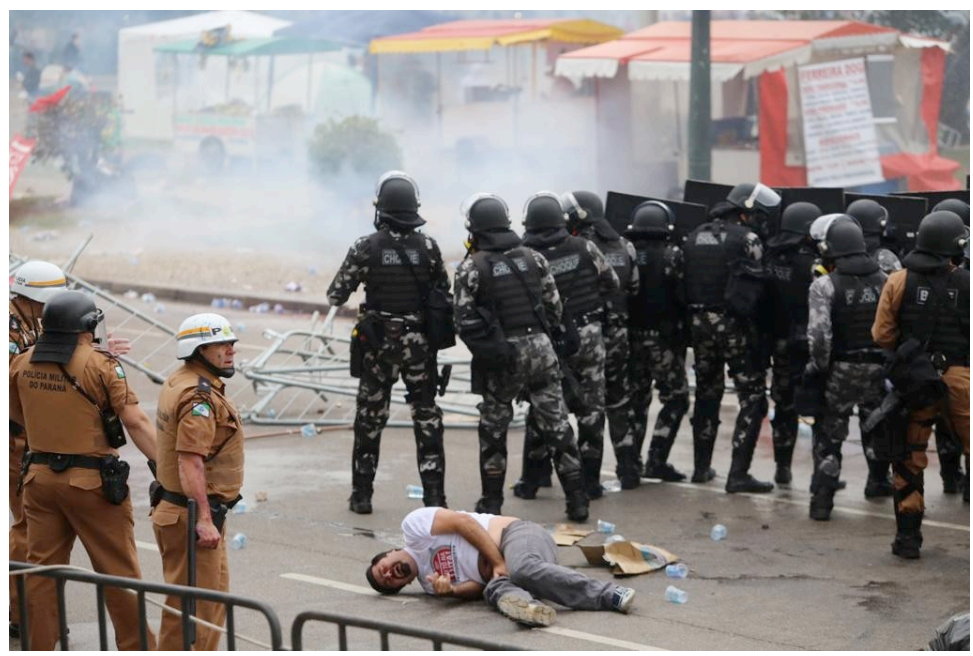

Imagem 2

Fonte: http://www.gazetadopovo.com.br/vida-publica/governo-do-parana-parabenizouos-policiais-da-batalha-docentro-civico-3vowcrxa0i0113p2ewsu2d8ot 


\section{SEMINÁRIO DE PESQUISA EM CIÊNCIAS HUMANAS - SEPECH \\ Humanidades, Estado e desafios didático-científicos \\ Londrina, 27 a 29 de julho de 2016}

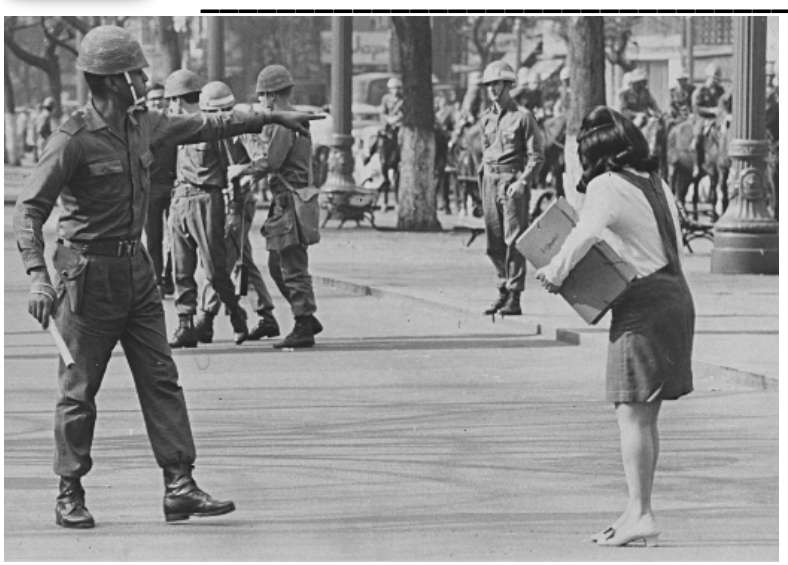

\section{Imagem 3}

Fonte: https://blogdaboitempo.com.br/2011/09/19/mulher-ou-militante/

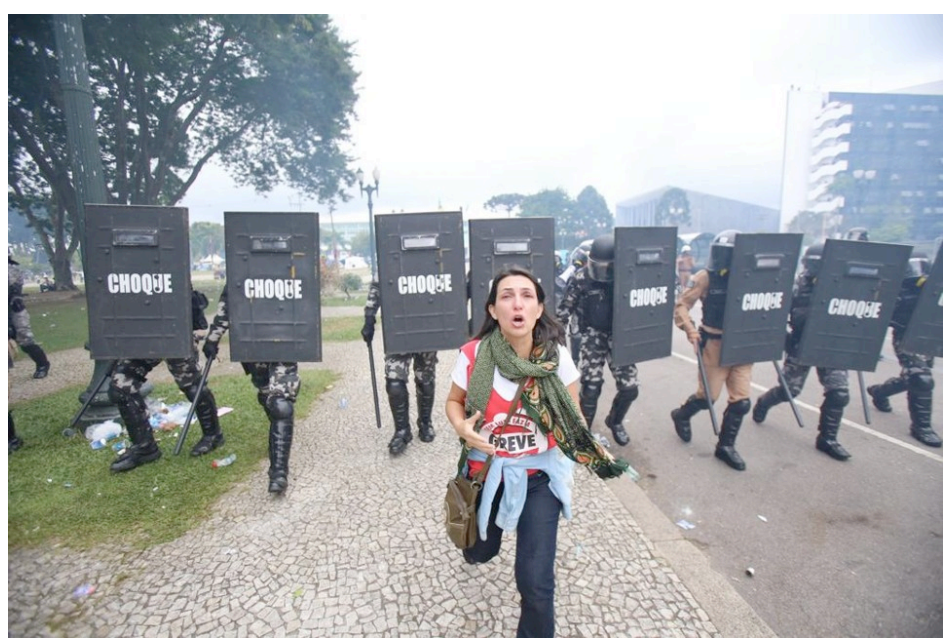

\section{Imagem 4}

Fonte: http://www.gazetadopovo.com.br/blogs/conexao-brasilia/cinco-pontos-paraentender-a-batalha-do-centro-civico/

O recorte das imagens, por meio da significação do simbólico, produz efeitos a partir da opacidade dos sentidos. As posições que os elementos ocupam nas imagens selecionadas são determinadas por sua exterioridade, significando, assim, na história. Ao direcionar nosso olhar para as imagens inseridas em diferentes épocas históricas, percebemos a retomada de discursos já existentes, que significam porque nenhum discurso é novo: já foram ditos em outra condição de produção, de outra forma.

$\mathrm{Na}$ opacidade da linguagem, ou seja, reconhecendo a multiplicidade dos sentidos, o sujeito, que é clivado ideologicamente, é sempre constituído em relação a outro. Dessa forma,

Dizemos que as contradições ideológicas que se desenvolvem através da unidade da língua são constituídas pelas relações contraditórias que mantém, necessariamente, entre si "os processos discursivos", na medida em que se inscrevem em relações ideológicas de classes. (PÊCHEUX, 2014, p. 83-84) 


\section{SEMINÁRIO DE PESQUISA EM CIÊNCIAS HUMANAS - SEPECH \\ Humanidades, Estado e desafios didático-científicos \\ Londrina, 27 a 29 de julho de 2016}

As posições sujeito são, então, pautadas na relação identidade vs. alteridade: sob a perspectiva materialista do discurso, reconhecemos os policiais a partir de suas formações discursivas e ideológicas, que não são correspondentes às formações que os manifestantes contra os governos dos momentos históricos possuem. Há, simbolicamente, sujeitos perpassados pela violência e pela censura agindo com sujeitos cindidos por ideologias ligadas às manifestações e à busca de direitos, pois, como afirma Pêcheux (2014: 147) "o sentido é determinado pelas posições ideológicas que estão em jogo no processo sócio-histórico no qual as palavras, expressões e proposições são produzidas."

Para Althusser (1980: 31), "o Estado é uma <máquina>de repressão que permite às classes dominantes assegurar sua dominação sobre a classe operária". Ao propor a diferença pelo funcionamento entre os Aparelhos Ideológicos de Estado (AIE) e Aparelhos Repressivos de Estado (ARE), o autor classificou a polícia como ARE por funcionar pela violência.

A truculência dos militares, representada nas quatro imagens, tem efeito de sentido porque essa ação corresponde a sua formação discursiva e as condições de produção assim permitem, assim como os manifestantes contra a ditadura e o governo Richa ocupam posições de subjetividade determinadas discursiva e ideologicamente.

Em nosso recorte, a imagem, interdiscursivamente, funciona como operador de memória social e promove o funcionamento da ideologia,

comportando no interior dela mesma um programa de leitura, um percurso escrito discursivamente em outro lugar: é o efeito de repetição e de reconhecimento que faz da imagem como que a recitação de um mito. A imagem mostraria como ela se lê. Será? A meu ver, assim como qualquer materialidade significante, também a imagem não é transparente. É materialidade. Tem seu modo de funcionamento. Interpreta-se. (ORLANDI, 2012: 63)

Ao percebermos os efeitos de sentido possíveis por meio da leitura do material, a memória opera como

uma esfera plena, cujas bordas seriam transcendentais históricos e cujo conteúdo seria um sentido homogêneo, acumulado ao modo de um reservatório: é necessariamente um espaço móvel de divisões, de disjunções, de deslocamentos e de retomadas, de conflitos de regularização... Um espaço de desdobramentos, réplicas, polêmicas e contra-discursos. (PÊCHEUX, 2007: 56)

A memória discursiva aciona a condição do dizer ao relacionar-se com o discurso, produzindo, assim, a ressignificação de enunciados marcados ideologicamente, afetados pelos esquecimentos.

\section{CONSIDERAÇÕES}

Ao tomar as imagens enquanto discurso, vimos que, para que significassem na atualidade, foi preciso que outras significassem antes, como explica Orlandi (2007: 85) 


\section{SEMINÁRIO DE PESQUISA EM CIÊNCIAS HUMANAS - SEPECH \\ Humanidades, Estado e desafios didático-científicos \\ Londrina, 27 a 29 de julho de 2016}

Pode-se dizer ainda que o discurso inscreve-se na tensão entre o mesmo e o diferente, entre o já-dito e o a-se-dizer, sendo atravessado por vários outros que o precederam e que já estão postos em outros contextos sociais. Esses dizeres já-ditos e esquecidos, que sustentam e tornam possível todo o dizer, constituem a memória discursiva ou interdiscurso. Assim, para que nossas palavras tenham sentido é preciso que elas já façam sentido.

A memória e o esquecimento operam, em uma visão materialista do discurso, segundo uma historicidade que afeta as posições sujeito previamente marcadas. É importante lembrar que todos os pontos citados aqui não são tomados como únicos e verdadeiros, pois a Análise de Discurso não procura a evidência presente nas respostas: ela trabalha com a opacidade dos efeitos de sentido, que são múltiplos, em busca de descrever como os discursos significam na sociedade. Esses efeitos

são impostos não pelo sujeito, mas pela formação discursiva. Dito de outra forma, eles se impõem àquele que, no seu interior, ocupa um lugar de enunciação, fazendo parte integrante da formação discursiva, ao mesmo título que as outras dimensões da discursividade. (MAINGUENEAU, 1997: 46)

Devemos destacar, ainda, que as posições ocupadas, as formações discursivas existentes só foram possíveis de serem descritas, porque a condição de produção dos enunciados assim permitiu. Os sentidos, como observamos, constituem-se no equívoco e são deslocados através da historicidade dos enunciados.

\section{REFERÊNCIAS}

ALTHUSSER, Louis. Ideologia e aparelhos ideológicos de estado. Lisboa: Presença, 1980.

MAINGUENEAU. Dominique. Novas tendências em Análise do Discurso. 3. ed. Campinas: Pontes, 1997.

ORLANDI, Eni Puccinelli. Discurso em análise: sujeito, sentido, ideologia. Campinas: Pontes, 2012.

2007.

Análise de discurso: princípios e procedimentos. 7. ed. Campinas: Pontes,

.Análise de discurso: princípios e procedimentos. 12. ed. Campinas: Pontes, 2015.

PÊCHUEX, Michel. Semântica e discurso: uma crítica à afirmação do óbvio. 5. ed. Campinas: EdUnicamp, 2014. 


\section{SEMINÁRIO DE PESQUISA EM CIÊNCIAS HUMANAS - SEPECH}

Humanidades, Estado e desafios didático-científicos

Londrina, 27 a 29 de julho de 2016

Papel da memória. In: ACHARD, P. (et al). Papel da memória. Campinas: Editores, 2007. p. 49-57. 